\title{
EDITORIAL
}

\section{Sleep research and mental illness}

What light has been thrown on mental illness by 15 years of expensive research into sleep? Mostly it has employed electroencephalography and, just as in the early days of human electroencephalography it was hoped that the waking brain waves would provide an objective index of personality differences or of brain changes in illnesses such as schizophrenia, so there were similar hopes for the intensive study of the sleeping brain; in both instances the results have been disappointing, except for the known organic disorders. Functional disorders remain functional. On a technical level the EEG studies have demonstrated that little reliance should be placed upon nurses' intermittent judgements of the presence of sleep: because a patient is lying still with eyes closed it does not mean he is asleep (Kupfer et al., 1970b; Weiss et al., 1973; Johns et al., 1974).

When rapid eye movement (REM, paradoxical) sleep was delineated, it was thought to be the stage in which all dreaming occurred. The similarities between dream thinking and schizophrenic thinking had often been remarked, and so there were hopes for some special link between this stage of sleep and schizophrenia. These hopes were early buoyed up by suggestions that selective deprivation of REM sleep led to psychotic experiences (Fisher and Dement, 1963). Studies of the sleep of schizophrenics have demonstrated that in the active phase of the illness there may be severe insomnia, but Kupfer et al. (1970a) concluded that marked sleep disturbance is not a necessary precursor of schizophrenic exacerbation, that REM sleep disorder is not prominent, and that the overall degree of sleep disturbance correlates with the severity of the psychotic symptoms in a manner that suggests that any sleep disorder is a non-specific concomitant of the intense distress. There remains one tantalizing problem: Zarcone et al. (1968) deprived schizophrenic patients of REM sleep by selective awakenings and noted that in the acute schizophrenics there was an absence of the expected rebound or 'compensatory' increase of REM sleep when undisturbed sleep was subsequently allowed. Recently a careful study from N.I.M.H. and St. Elizabeth's Hospital, Washington, D.C., reports eight actively ill schizophrenics and eight non-psychotic control patients in whom selective awakenings were made from REM sleep. The authors, Gillin et al. (1974), found that the schizophrenics had a significantly smaller rebound than did the controls. The findings could not be attributed to differences in drugs, age, sex, REM sleep during the deprivation period, or to total sleep during the deprivation or the recovery periods. The authors stress that, despite their overall finding, there was considerable overlap between the two groups.

In so far as affective disorders are concerned there is ample evidence that anxiety, even the anxiety experienced by healthy persons on their first night in a sleep laboratory, or after viewing an anxietyprovoking movie, will cause more awakenings during the night, especially from REM sleep, shorter total sleep, and a lesser proportion of REM sleep. Spontaneous galvanic skin responses or GSRs are more marked during wakefulness in anxious patients and it is curious that there are what have been described as 'GSR storms' in what is often regarded as the very deepest sleep-namely, stages 3 and 4 non-rapid eye movement sleep with large EEG slow waves. These electrodermographic fluctuations have been reported as increased on nights following daytime emotional stress, such as examinations (Lester et al., 1967).

In the case of depressed patients many studies have confirmed that these patients do indeed have sleep that is fragmented and light, with an increase in periods spent awake or drowsy (Mendels and Hawkins, 1971). Most of the reports have suggested a relative deficiency of stage 4 sleep (with the largest slow waves) and there have been a variety of features pointing to a disturbance of REM sleep. It has been difficult to disentangle the powerful effects of drugs and their persisting aftereffects, but overall it seems that in many depressed patients, quite apart from drugs, there is an increased 'pressure' towards REM sleep, leading to its appearance in larger amounts and earlier in the night. Normally the first REM period occurs about an hour after falling asleep. In a group of 
moderately depressed patients, Kupfer and Foster (1972) reported a mean REM latency of 50 minutes, but the figure was 18 minutes in severe or psychotic depression.

Possibly this is a response to chronic shortage of total sleep, but further clues point to a special link between REM sleep and depression. There are many psychopharmacological agents that will somewhat reduce the amount of REM sleep, but few increase it. The chief exception is reserpine (Hartmann and Cravens, 1973), a drug notable for causing depression. By way of contrast, the mood-elevating drugs stand out from all others in being extremely powerful suppressants of REM sleep. This is true of the amphetamines (Oswald, 1970), the tricyclic antidepressants (Dunleavy et al., 1972), and the MAOIs. With MAOIs all signs of paradoxical sleep disappear after a delay of about 10 days from the time when an adequate daily dose was begun, and, in those patients who make a clinical response, restoration of normal mood coincides closely in time with the delayed abolition of the signs of REM sleep (Akindele et al., 1970; Wyatt et al., 1971; Dunleavy and Oswald, 1973). Unpublished work at Edinburgh with the new antidepressant viloxazine, chemically unrelated to other antidepressants, indicates an effect on REM sleep very similar to imipramine.

Some years ago G. W. Vogel in the U.S.A. reported that selective deprivation of REM sleep, by means of awakenings, improved the mood of depressed patients and now a careful double-blind study confirms that selective deprivation of REM sleep by awakenings, and not just drug-induced selective deprivation, is effective in relieving endogenous depression (Vogel et al., 1975).

Organic brain disturbances investigated by sleep research techniques have led to clearer answers. Feinberg et al. (1967) compared the sleep of normal young and normal elderly people with the sleep of patients diagnosed as suffering from chronic brain syndrome (organic dementia). The greater the deterioration of the brain, the more the disturbance of sleep, whether the deterioration stemmed from the normal ageing process, or from an accelerated decline. The demented patients, compared with the normal elderly patients, took longer to fall asleep, woke more frequently, and got less total sleep. REM sleep appeared with short latency, but occupied a smaller percentage of total sleep and the eye movements themselves were less profuse. Slow wave sleep stages 3 and 4 were reduced, and the severity of intellectual impairment was highly correlated with the severity of the sleep disorder.

Mentally subnormal patients as a general category have been found to have a remarkable deficiency both of time spent in REM sleep, and in the number and distribution of eye movements during it (Feinberg et al., 1969; Petre-Quadens, 1969). This research into the shrunken brain of dementia and the poorly functioning brain of the mentally subnormal contributes to the evidence linking REM sleep with synthetic processes in the brain, whether for maintenance of brain substances or for plastic or learning mechanisms.

The actions of many psychoactive drugs have been investigated using sleep research techniques (Oswald, 1973) and, among other things, it has become clear that when there has been established some degree of dependency upon drugs such as dexamphetamine or heroin, many weeks are needed for brain function to return to normal after the drug is stopped (Oswald and Thacore, 1963; Lewis et al., 1970). The delirium caused by alcohol or the withdrawal of sleeping pills has been found to be characterized by excessive REM sleep (Gross et al., 1966; Greenberg and Pearlman, 1969; Haider and Oswald, 1970). Alcohol and hypnotics relieve anxiety, increase sleep, reduce restlessness, reduce time spent in REM sleep, and also reduce the bizarreness of dreams (Firth, 1974). In their withdrawal can be seen the opposite features-namely, fear, insomnia, restlessness, and REM sleep that intrudes even into wakefulness accompanied by bizarre dreams, the hallucinatory state of delirium tremens.

Sleep research has not had dramatic effects on psychiatric practice or knowledge but has made, and will continue to make, a contribution to the steady advance that comes on many fronts. There are not many easily-measurable human brain functions but electrophysiological techniques offer quite a number during sleep and it is a time that has certain special advantages for study, there being a relative freedom from ephemeral environmental influences. 


\section{REFERENCES}

Akindele, M. O., Evans, J. I., and Oswald, I. (1970). Monoamine oxidase inhibitors, sleep and mood. Electroencephalography and Clinical Neurophysiology, 29, 47-56.

Dunleavy, D. L. F., Brezinova, V., Oswald, I., Maclean, A. W. and Tinker, M. (1972). Changes during weeks in effects of tricyclic drugs on the human sleeping brain. British Journal of Psychiatry, 120, 663-672.

Dunleavy, D. L. F., and Oswald, I. (1973). Phenelzine, mood response, and sleep. Archives of General Psychiatry, 28, 353-356.

Feinberg, I., Braun, M., and Shulman, E. (1969). EEG sleep patterns in mental retardation. Electroencephalography and Clinical Neurophysiology, 27, 128-141.

Feinberg, I., Koresko, R. L., and Heller, N. (1967). EEG sleep patterns as a function of normal and pathological aging in man. Journal of Psychiatric Research, 5, 107-144.

Firth, H. (1974). Sleeping pills and dream content. British Journal of Psychiatry, 124, 547-553.

Fisher, C., and Dement, W. C. (1963). Studies on the psychopathology of sleep and dreams. American Journal of Psychiatry, 119, 1160-1168.

Gillin, J. C., Buchsbaum, M. S., Jacobs, L. S., Fram, D. H., Williams, R. B., Jr, Vaughan, T. B., Jr, Mellon, E. Snyder, F., and Wyatt, R. J. (1974). Partial REM sleep deprivation, schizophrenia and field articulation. Archives of Gencral Psychiatry, 30, 653-662.

Greenberg, R., and Pearlman, C. (1967). Delirium tremens and dreaming. American Journal of Psychiatry, 124, 133-142.

Gross, M. M., Goodenough, D., Tobin, M., Halpert, E. Lepore, D., Perlstem, A., Sirota, M., Dibianco, J., Fuller, R., and Kishner, I. (1966). Sleep disturbances and hallucinations in the acute alcoholic psychoses. Journal of Nervous and Mental Diseases, 142, 493-514.

Haider, I., and Oswald, I. (1970). Late brain recovery processes after drug overdose. British Medical Journal, 2 318-322.

Hartmann, E., and Cravens, J. (1973). The effects of long term administration of psychotropic drugs on human sleep: 2 The effects of reserpine. Psychopharmacologia (Berl.) 33, 169-184.

Johns, M. W., Large, A. A., Masterton, J. P., and Dudley, H. A. F. (1974). Sleep and delirium after open heart surgery. British Journal of Surgery, 61, 377-381.
Kupfer, D. J., and Foster, F. G. (1972). Interval between onset of sleep and rapid-eye-movement sleep as an indicator of depression. Lancet, 2, 684-686.

Kupfer, D. J., Wyatt, R. J., Scott, J., and Snyder, F. (1970a). Sleep disturbance in acute schizophrenic patients. American Journal of Psychialry, 126, 1213-1223.

Kupfer, D. J., Wyatt, R. J., and Snyder, F. (1970b). Comparison between electroencephalographic and systematic nursing observations of sleep in psychiatric patients. Journal of Nervous and Mental Disease, 151, 361-368.

Lester, B. K., Burch, N. R., and Dossett, R. C. (1967). Nocturnal EEG-GSR profiles: the influence of presleep states. Psychophysiology, 3, 238-248.

Lewis, S. A., Oswald, I., Evans, J. I., Akindele, M. O., and Tompsett, S. L. (1970). Heroin and human sleep. Electroencephalography and Clinical Neurophysiology, 28, 374-381.

Mendels, J., and Hawkins, D. R. (1971). Sleep and depression. 4. Longitudinal studies. Journal of Nervous and Mental Disease, 153, 251-272.

Oswald, I. (1970). Effects on sleep of amphetamine and its derivatives. In Amphetamines and Related Compounds, pp. 865-871. Edited by E. Costa and S. Garattini. Raven Press: New York.

Oswald, I. (1973). Drug research and human sleep. Annual Review of Pharmacology, 13, 243-252.

Oswald, I., and Thacore, V. R. (1963). Amphetamine and phenmetrazine addiction. British Medical Journal, 2, 427-431.

Petre-Quadens, O. (1969). Contribution à l'Etude de la Phase dite Paradoxale du Sommeil. Acta Medica Belgica: Bruxelles.

Vogel, G. W., Thurmond, A., Gibbons, P., Moore, S., Edwards, K., Sloan, K., Sexton, K., Boyd, M., Walker, M., Miller, S., and Deen, L. (1975). The effect of REM deprivation on depressive syndromes. Archives of General Psychiatry. (In press.)

Weiss, B. L., McPartland, R. J., and Kupfer, D. J. (1973). Once more: the inaccuracy of non-EEG estimations of sleep. American Journal of Psychiatry, 130, 1282-1285.

Wyatt, R. J., Fram, D. H., Kupfer, D. J., and Snyder, F. (1971). Total prolonged drug-induced REM sleep suppression in anxious-depressed patients. Archives of General Psychiatry, 24, 145-155.

Zarcone, V., Gulevich, G., Pavik, T., and Dement, W. (1968). Partial REM phase deprivation and schizophrenia. Archives of General Psychiatry, 18, 194-202. 